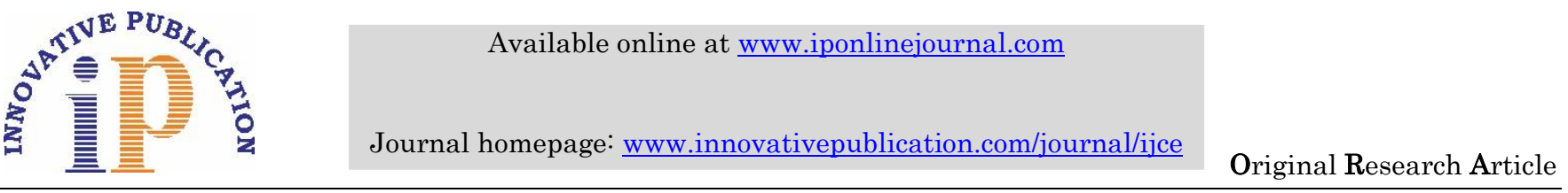

\title{
Comparative evaluation of canal transportation and centering ability of three single file systems
}

\author{
Akriti Goel $^{1 *}$, A.P. Tikku², Anil Chandra ${ }^{3}$ \\ ${ }^{\mathbf{1}}$ Senior Resident, ${ }^{2}$ Professor and Head, ${ }^{3}$ Professor, Dept. of Conservative Dentistry \& Endodontics, King George's Medical University, \\ Lucknow, Uttar Pradesh, India
}

\begin{abstract}
Aim: The present in-vitro study compared the shaping effects like original canal curvature preserving ability and transportation of canal lumen following root canal preparation by three rotary single file systems, Reciproc, WaveOne, and OneShape, in teeth with curved root canals using cone-beam computed tomographic imaging technique.

Materials and Methods: Sixty mesiobuccal roots of mandibular first molars extracted for periodontal reasons with completely formed root apex having canal length of at least $18 \mathrm{~mm}$, with canal curvature of $15^{\circ}-30^{\circ}$ (Schneider method) from middle level of root length, were selected for this study. Samples were randomly divided into 3 groups according rotary file used in canal preparation namely; Reciproc (VDW, Munich, Germany), WaveOne (Dentsply Maillefer, Ballaigues, Switzerland), and OneShape (Micro Méga, Besançon, France) systems, with 20 teeth each. Diagnostic and post instrumentation Cone-beam computed tomography (CBCT) radiographs were taken for each sample. Apical transportation was calculated at distances of $2 \mathrm{~mm}, 3 \mathrm{~mm}$, and $4 \mathrm{~mm}$ from the root apex. The data were tabulated and statistically analyzed using analysis of variance (ANOVA) and post-hoc Tukey's HSD test and level of significance was set at a palue $<0.05$.

Results The mean canal transportation was found to be significantly lower with OneShape ( $<<0.001)$ followed by the WaveOne rotary system at all root levels studied. Also, the centering ability of OneShape file system was higher than that of the WaveOne and Reciproc.

Conclusions: The OneShape rotary system showed the lowest transportation of canal lumen in both the mesiodistal and buccolingual directions and the highest centering ability contrary to the Reciproc system, which showed the highest transportation and the lowest centering ability.
\end{abstract}

Keywords: OneShape, Reciproc, Root canal preparation, Single file, Transportation, WaveOne.

\section{Introduction}

The primary goal of an endodontic treatment is to achieve through cleaning and shaping of the root canal, giving it a conical shape in the direction of crown to apex, along with maintaining its initial path and preserving the original curvature. ${ }^{1}$ This, however is difficult to achieve in case of curved canals as progressive instrumentation leads to alteration in canal curvature. Such divergence from its original shape, cause iatrogenic errors like formation of ledge, strip perforation and zipping of the canal. During cleaning and shaping, transportation of foramen has a negative impact on the quality of the filling of the root canals and subsequently effectiveness of the seal leading to endodontic failure. ${ }^{2}$

Since the introduction of nickel-titanium (NiTi) instruments, the use of rotary instruments intended for biomechanical canal preparation, has revolutionized endodontic therapy making it faster, reducing operator fatigue and treatment time and allowing fewer procedural errors associated with the use of stainless steel instruments, ${ }^{3}$ hence, reducing the chair side time of the treatment. ${ }^{4}$ Reciproc (VDW, Munich, Germany) is a single-file system which is made from M-Wire NiTi alloy with S-shaped cross-section and a regressive taper that allows increased flexibility and resistance to cyclic fatigue. This rotary system is used in reciprocation to complete the canal preparation enabling the instrument to move through the root canal without a glide path. ${ }^{5}$ WaveOne (Dentsply Maillefer, Ballaigues, Switzerland) is another single-file shaping system, made up of M-Wire NiTi alloy having reverse helix and 2 distinct cross- sections on the length with modified convex triangular cross section that utilizes unequal clock-wise (CW) / counter clock-wise (CCW) angles. The presence of deeper flutes enable increased flexibility, which makes the instrument apt for preparation of curved canals. ${ }^{5}$ OneShape (Micro Méga, Besançon, France) is another single-file rotary instrument made up of NiTi alloy having constant taper with different cross sectional design over its entire working length and variable pitch length, making it desirable to be used in continuous rotary motion. ${ }^{6}$

Cone-beam computed tomographic (CBCT) is three dimensional imaging technique that gives sectional images for an accurate and precise endodontic diagnosis. It can be helpful for differential diagnosis of periapical lesions, revealing complex anatomy of the root canal system which cannot be differentiated in a two dimensional radiograph. CBCT is also useful in the identification of lateral and accessory canals, internal and external resorption and detection of vertical root fracture which can rarely be seen

*Corresponding Author: Akriti Goel, Dept. of Conservative Dentistry \& Endodontics, King George's Medical University, Lucknow, Uttar Pradesh, India

Email: akriti.dentist@gmail.com

http://doi.org/10.18231/j.ijce.2019.020 
otherwise. CBCT can be used as diagnostic aid for measurements before and after instrumentation of the root canals, in determining the amount of dentin removed during instrumentation of root canals. It permits exact analyses of variables such as volume, surface area, cross-sectional shape, and taper ${ }^{6}$ The present study aimed to compare canal transportation and the centering ability of the following three single-file systems: Reciproc, WaveOne and OneShape in curved root canals using CBCT imaging.

\section{Materials and Methods Sample selection}

Sixty mesiobuccal root canals from human permanent mandibular first molars teeth, extracted for periodontal reasons, caries free, non-carious lesion free accompanied by normal anatomical form and structure, were taken. The selection criteria included a completely formed root apex, $15^{\circ}-30^{\circ}$ canal curvature (according to the Schneider method), ${ }^{7}$ curvature radius $<10^{\circ}$, a minimum length of 18 $\mathrm{mm}$, uncalcified canals, and Type IV Vertucci canals (two separate canals $)^{8}$

\section{Sample preparation}

The access cavity was prepared using a round carbide bur with subsequent use of EndoZ bur (Dentsply Maillefer, Ballaigues, Switzerland) for de-roofing of pulp chamber. In order to determine the working length, a hand \#10 K-file (Dentsply Maillefer, Ballaigues, Switzerland) was inserted into the root canal. $1 \mathrm{~mm}$ from the file length was reduced, when the file emerged from the apical foramen, to establish the working length. The teeth were then mounted on an acrylic base and stabilized using putty silicone impression material (Speedex, Coltene Whaledent, Altstatten, Switzerland). All teeth were then scanned with the CBCT device (Sirona Dental System Inc, Bensheim, Germany). Distances $2 \mathrm{~mm}, 3 \mathrm{~mm}$, and $4 \mathrm{~mm}$ from the root apex were accounted for in the CBCT images to assess canal transportation and centering ability of studied file systems.

\section{Root Canal Preparation}

The biomechanical root canal preparation in all the groups was performed by single operator. Glide path was prepared with K-file \#10 and K-file \#20. Group I was prepared using Reciproc with $8 \%$ taper and a $0.25 \mathrm{~mm}$ tip size. Group II was prepared using WaveOne having $8 \%$ taper and $0.25 \mathrm{~mm}$ tip size and Group III was prepared using OneShape having 6\% taper and $0.25 \mathrm{~mm}$ tip size. Each file was used to prepare 5 canals and then discarded. CanalPro2 (Coltene Whaledent, Switzerland) endomotor was used to prepare the canals during biomechanical preparation. Throughout biomechanical preparation, during instrumentation with each file, the canals were irrigated with $5 \mathrm{ml} 2.5 \%$ normal saline and $2 \mathrm{ml}$ of $3.0 \%$ sodium hypochlorite. Each instrument was inserted into the canal in slow pecking motion till working length.
Evaluation of canal transportation and centering ability After preparation of the root canals, CBCT images were repeated for all the teeth. Both mesiodistal and buccolingual diameters were recorded at $2 \mathrm{~mm}, 3 \mathrm{~mm}$ and $4 \mathrm{~mm}$ from the apex in both the diagnostic and postoperative CBCT scans. (Fig. Apical transportation was determined using the following formulae:

\section{(a1-a2)-(b1-b2)}

Where, a1 is the least distance between mesial borders of the root and the canal before instrumentation, a 2 is the least distance between mesial borders of the root and the canal after instrumentation, $\mathrm{b} 1$ is the least distance between distal borders of the root and the canal before instrumentation, and b2 is the least distance between distal borders of the root and the canal after instrumentation.

(c1-c2)-(d1-d2)

In this formula, $\mathrm{c} 1$ is the least distance between the buccal borders of the root and the canal before instrumentation, c2 is the least distance between the buccal borders of the root and the canal after instrumentation, $\mathrm{d} 1$ is the least distance between the lingual borders of the root and the canal before instrumentation, and $\mathrm{d} 2$ is the least distance between the lingual borders of the root and canal after instrumentation.

According to these formulas, ' 0 ' means no canal transportation, whereas positive and negative values show mesial or buccal and distal or lingual transportation, respectively.

Centering ability was determined by:

\section{a1-a2/b1-b2 or b1-b2/ a1-a2}

In these formulae, the fraction with the lesser value was selected for statistical analysis. According to these formulas, 1 represents complete centering, whereas other values show changes in the canal pathway. ${ }^{8}$

\section{Statistical analysis}

Statistical analysis was performed using analysis of variance (ANOVA) and post-hoc Tukey's HSD test and level of significance set at a $\mathrm{p}$ value $<0.05$ using SPSS 19 software (IBM Corporation, Chicago).

\section{Results}

In the present in-vitro study, at all the levels from the apex, precisely; $2 \mathrm{~mm}, 3 \mathrm{~mm}$ and $4 \mathrm{~mm}$ distance, the Reciproc (Group I) system showed highest canal transportation with least centering ability as compared to other file systems studied. The observed difference in canal transportation in the 3 groups was statistically significant $(\mathrm{p}<0.001)$, except when comparing for the $4 \mathrm{~mm}$ distance from root apex in which the buccolingual transportation was not statistically significant between the Reciproc and WaveOne groups ( $\mathrm{p}=$ 0.589). In, OneShape rotary file system, highest centering ability was observed, while Reciproc showed the lowest under the experimental conditions. (Table 1) Results 
Table 1: Canal Transportation (Mean \pm SD) and Centering Ration of the experimental rotary single file systems

\begin{tabular}{|c|c|c|c|c|}
\hline $\begin{array}{c}\text { Rotary Single } \\
\text { File systems }\end{array}$ & $\begin{array}{c}\text { Distance from } \\
\text { apex }(\mathbf{m m})\end{array}$ & $\begin{array}{c}\text { Mesiodistal transportation } \\
(\mathbf{m m})(\mathbf{M e a n} \pm \mathbf{S D})\end{array}$ & $\begin{array}{c}\text { Buccolingual transportation } \\
(\mathbf{m m})(\mathbf{M e a n} \pm \mathbf{S D})\end{array}$ & $\begin{array}{c}\text { Centering ratio } \\
\text { (Mean } \pm \text { SD) }\end{array}$ \\
\hline \multirow{3}{*}{$\begin{array}{c}\text { Reciproc } \\
\text { (Group I) }\end{array}$} & 2 & $0.09 \pm 0.021$ & $0.08 \pm 0.020$ & $0.52 \pm 0.058$ \\
\cline { 2 - 5 } & 3 & $0.08 \pm 0.028$ & $0.06 \pm 0.017$ & $0.54 \pm 0.081$ \\
\hline \multirow{3}{*}{$\begin{array}{c}\text { WaveOne } \\
\text { (Group II) }\end{array}$} & 4 & $0.06 \pm 0.018$ & $0.05 \pm 0.018$ & $0.59 \pm 0.071$ \\
\cline { 2 - 5 } & 2 & $0.05 \pm 0.016$ & $0.05 \pm 0.022$ & $0.61 \pm 0.052$ \\
\hline \multirow{2}{*}{$\begin{array}{c}\text { OneShape } \\
\text { (Group III) }\end{array}$} & 3 & $0.04 \pm 0.018$ & $0.04 \pm 0.018$ & $0.64 \pm 0.078$ \\
\cline { 2 - 5 } & 2 & $0.04 \pm 0.014$ & $0.04 \pm 0.021$ & $0.70 \pm 0.071$ \\
\cline { 2 - 5 } & 3 & $0.03 \pm 0.012$ & $0.02 \pm 0.013$ & $0.91 \pm 0.051$ \\
\hline
\end{tabular}

obtained while comparing the centering ability in the three file systems studied were statistically significant $(\mathrm{p}<$ $0.001)$.
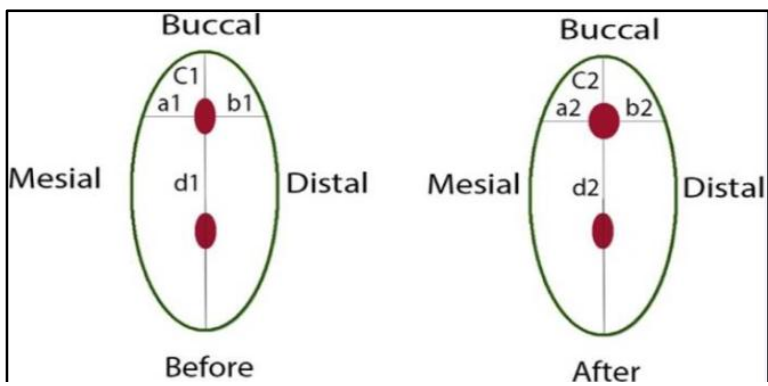

Fig. 1: Schematic presentation of the parameters taken for canal transportation.

\section{Discussion}

The primary objective of root canal preparation is thorough cleaning and shaping of the canal walls while maintaining the original form of the canal lumen. Adequate instrumentation (shaping) combined with effective irrigation is required to achieve sufficient disinfection. This aids in achieving the biological and mechanical objectives of the root canal treatment and finally helps to achieve a 3dimensional obturation. ${ }^{9}$ Curved canals provide a challenge during endodontic therapy, as all instruments and preparation techniques tend to alter the natural root canal pathway during biomechanical preparation. ${ }^{10}$ This primarily occurs due to rigid nature and lack of flexibility and shape memory of endodontic instruments used in the process, which may cause unequal distribution of forces at the point of contact with the root canal wall during biomechanical preparation. Therefore, as the instrument tends to regain its original shape rather then following canal anatomy, higher force concentration is created on the external surface at point of maximum root curvature, leading to canal transportation. ${ }^{11,12}$

Transportation can be either type I (mild form), type II (moderate) or type III (severe form). Literatures show that only type I transportation can be managed by nonsurgical endodontics while others require surgical intervention for adequate prognosis. ${ }^{13}$ Transportation of the root canal may lead to several iatrogenic errors like inadequate debridement of the apical root region and excessive removal of dentin in the coronal root region leading to zipping or perforation, resulting in poor prognosis of endodontically treated teeth. ${ }^{14}$ The purpose of this study was to compare the shaping ability in terms of canal transportation and centering ability of three instruments recommended for the preparation of curved canals.

The use of simulated root canals in resin blocks has the disadvantage of being unable to evaluate the root canal and its cross-section in a three-dimensional view. However, extracted natural teeth most precisely simulate the microenvironment of root canal preparation in the clinical condition, by providing compatibility of the apex to a specified instrument size, and the angle of curvature. ${ }^{15}$ Moreover, the mechanical properties of the resin are different from those of human teeth. So, in the present invitro study, extracted tooth roots were used.

CBCT three dimensional imaging is one the most viable radiographic tool employed for accurate diagnosis in invitro experimental researches, as it provides more reliable results in the evaluation of root canal transportation for clinical simulation. ${ }^{16}$ Several studies have been done aimed to compare apical transportation caused by rotary instruments with rotational and reciprocal motions and superiority of reciprocal motion has been proved time and again by various authors as literatures state that Single file reciprocation creates a cutting action that is much greater than disengagement, thereby allowing better apical progression and higher efficiency. ${ }^{17-20}$ However, You SY and Kim $\mathrm{HC}$ et al. ${ }^{21}$ found no difference between the two motions with respect to apical transportation. Although, most studies suggest that reciprocal motion is more effective in the prevention of apical transportation which might be attributed to the reduction of torsional and flexural stresses in reciprocating movement thereby increasing the canal centering ability of rotary instrument and reducing the taper lock within the root canal. ${ }^{22}$ Single-file Ni-Ti rotary systems are the choice of instruments in modern endodontic practice as they cause fewer canal transportation, by following the anatomy of the root canal; that is, the dentin removed on the inner and outer wall of the root canal should maintain the same proportion and cause less displacement of the apical foramen. ${ }^{23}$ This canal centering property of the instrument is mainly depended on its cross section design, flexibility, and 
alloy type used in manufacturing. Therefore, in the present experimental study, three single-file systems were used to see their effectiveness in the performance as instruments of choice for a successful endodontic therapy. ${ }^{24}$

In the present study, OneShape (Group III) had the lowest transportation and the highest centering ability. According to the literatures, ${ }^{6}$ this may be caused by the unique design of the One Shape instrument that incorporates a variety of different cross sections along the active length of the file, and offers an optimal and improved cutting action in three zones of the root canal. This asymmetrical design is alleged to eliminate threading and binding of the instrument in continuous rotation and minimal fatigue along the length of the entire file virtually eliminates the risk of accidental instrument separation. Oneshape instrument is made up of NiTi alloy and has a tip size of $25 \mathrm{~mm}$ with constant taper of $0.06 \mathrm{~mm}$. Its flexibility and unique continuous downward movement ensures a highly effective apical progression.

The Reciproc (Group I) and WaveOne (Group II) systems are made of M-Wire, which is only in the austenitic phase These files have a continuous taper over the first $3 \mathrm{~mm}$ of their working part followed by a decreasing taper. ${ }^{25}$ In the present study, WaveOne single file rotary systems showed higher centering ability and lesser canal transportation as compared to Reciproc file system. Ferreira MM and Rebelo $\mathrm{D}$ et $a l .{ }^{26}$ found in their study, that WaveOne rotary system is an effective instrumentation system which prevents transportation of the root canal and also maintains its anatomical position. This finding is consistent with the present study. These findings are also corroborated by Gergi $\mathrm{R}$ and Arbab-Chirani $\mathrm{R}$ et al. ${ }^{27}$ who reported that the centering ability in the WaveOne system is higher than the Reciproc system. Another study by, Capar ID and Ertas H et $a l .{ }^{28}$ compared six different rotary systems in transportation, canal curvature, centering ratio, surface area, and volumetric changes of severely curved root canals using CBCT images. They found that there was no significant difference in the performance of these rotary systems. Moreover, in the present study, none of the instrumentation systems used caused more than $0.3 \mathrm{~mm}$ of transportation. As, according to Wu MK and Fan B et al. ${ }^{29}$ apical transportation more than $0.3 \mathrm{~mm}$ may affect the success of endodontic treatment by compromising the seal of the obturating material.

The present study being an in-vitro has the limitation of experimental studies in which the simulation of clinical scenarios is difficult along with the sample size of the study that possibly posed major limitation on the outcome of results. It is recommended that further studies would be performed evaluating different aspects of performance of the endodontic rotary file systems studied.

\section{Conclusion}

The OneShape rotary file system possessed the lowest transportation in both the mesiodistal and buccolingual directions and the highest centering ability, whereas the Reciproc system showed the highest transportation and the lowest centering ability. Therefore, within the limitations of the present experimental study it can be ascertained that Single file Oneshape system is suitable instrument for the root canal preparation in curved canals.

\section{Source of Funding}

None.

\section{Conflict of Interest}

None.

\section{References}

1. Nazari MK, Mehran M, Farajian ZH. Root canal cleaning efficacy of rotary and hand files instrumentation in primary molars. Iran Endod J 2009;4:53-7.

2. Abou-Rass M, Frank AL, Glick DH. The anticurvature filing method to prepare the curved root canal. J Am Dent Assoc 1980;101:792-4.

3. Short JA, Morgan LA, Baumgartner JC. A comparison of canal centering ability of four instrumentation techniques. J Endod 1997;23:503-7.

4. McSpadden JT. Mastering Endodontic Instrumentation. Cloudland Institute, Chattanooga, TN; Arbor Books Inc., Canada; 2007:1-134.

5. Kim H-C, Kwak S-W, Cheung GS-P, Cyclic fatigue and torsional resistance of two new nickel-titanium instruments used in reciprocation motion: Reciproc versus WaveOne. $J$ Endod 2012;38:541-4.

6. Scarfe WC, Levin MD, Gane D, Farman AG. Use of cone beam computed tomography in endodontics. Int J Dent 2009;2009:2634567.

7. Schneider SW. A comparison of canal preparations in straight and curved root canals. Oral Surg Oral Med Oral Pathol 1971;32:271-5.

8. Gergi R, Rjeily JA, Sader J, Naaman A. Comparison of canal transportation and centering ability of twisted files, PathfileProTaper system, and stainless steel hand K-files by using computed tomography. J Endod 2010;36:904-7

9. Walton RE. Histologic evaluation of different methods of enlarging the pulp canal space. J Endod 1976;2:304-11.

10. Zhang R, Hu T. Root canal curvature. Int Endod J 2010;43:616-8.

11. Javaheri HH, Javaheri GH. A comparison of three Ni-Ti rotary instruments in apical transportation. J Endod 2007;33:284-6.

12. Peters OA. Current challenges and concepts in the preparation of root canal systems: a review. J Endod 2004;30:559-67.

13. Gluskin AH, Peters CI, Wong RD, Ruddle CJ. Retreatment of nonhealing endodontic therapy and management of mishaps. In: Ingle IJ, Bakland KL, Baumgartner CJ, editors. Ingle's endodontics 6. Lewiston, NY: BC Decker; 2008:1088-161.

14. Karabucak B, Gatan AJ, Hsiao C, Iqbal MK. A comparison of apical transportation and length control between EndoSequence and Guidance rotary instruments. $J$ Endod 2010;36:123-5.

15. Khalilak Z, Fallahdoost A, Dadresanfar B, Rezvani G. Comparison of extracted teeth and simulated resin blocks on apical canal transportation. Iran Endod J 2008;3:109.

16. H€ulsmann M, Peters OA, Dummer PM. Mechanical preparation of root canals: shaping goals, techniques and means. Endod Topics 2005;10:30-76.

17. Filho EMM, de Castro Rizzi C, Coelho MB, Shaping ability of Reciproc, UnicOne, and ProTaper Universal in simulated root canals. Sci World J 2015;690854:1-6

18. Tambe VH, Nagmode PS, Abraham S. Comparison of canal transportation and centering ability of rotary protaper, one 
shape system and wave one system using cone beam computed tomography: an in vitro study. J Conserv Dent 2014;17:561-5.

19. Dhingra A, Ruhal N, Miglani A. Evaluation of single file systems Reciproc, OneShape, and WaveOne using cone beam computed tomography-an in vitro study. J Clin Diagn Res 2015;9:ZC30.

20. Saber S, Nagy M, Sch€afer E. Comparative evaluation of the shaping ability of WaveOne, Reciproc and OneShape singlefile systems in severely curved root canals of extracted teeth. Int Endod J 2015;48:109-14.

21. You SY, Kim HC, Bae KS. Shaping ability of reciprocating motion in curved root canals: a comparative study with microcomputed tomography. J Endod 2011; 37:1296-300.

22. Gergi R, Osta N, Bourbouze G. Effects of three nickel titanium instrument systems on root canal geometry assessed by microcomputed tomography. Int Endod J 2015;48:162-70.

23. Prabhakar AR, Yavagal C, Dixit K, Naik SV. Reciprocating vs rotary instrumentation in pediatric endodontics: cone beam computed tomographic analysis of deciduous root canals using two single-file systems. Int J Clin Pediatr Dent 2016;9:45.

24. Xu X, Eng M, Zheng Y, Eng D. Comparative study of torsional and bending properties for six models of nickeltitanium root canal instruments with different cross-sections. $J$ Endod 2006;32:372-5.
25. Simpsy GS, Sajjan GS, Mudunuri P, et al. Shaping ability of reciprocating motion of WaveOne and HyFlex in moderate to severe curved canals: a comparative study with cone beam computed tomography. J Conserv Dent 2016;19:578-82.

26. Ferreira MM, Rebelo D, Caramelo F. In vitro evaluation of wear and canal transportation using reciprocating instruments: RECIPROC $^{\circledR}$ vs WaveOne ${ }^{\circledR}$ files. Rev Port Estomatol Cir Maxilofac 2013;54:117-23.

27. Gergi R, Arbab-Chirani R, Osta N, Naaman A. Microcomputed tomographic evaluation of canal transportation instrumented by different kinematics rotary nickel- titanium instruments. J Endod 2014;40:1223-7.

28. Capar ID, Ertas H, Ok E, et al. Comparative study of different novel nickel-titanium rotary systems for root canal preparation in severely curved root canals. J Endod 2014;40:852-6.

29. Wu MK, Fan B, Wesselink PR. Leakage along apical root fillings in curved root canals. Part I: effects of apical transportation on seal of root fillings. J Endod 2000;26:210-6.

How to cite this article: Goel A, Tikku AP, Chandra A. Comparative evaluation of canal transportation and centering ability of three single file systems using CBCT. Indian $J$ Conserv Endod 2019;4(3):86-90. 